\title{
Tri-beam FIB Sample Preparation to Study Alterations in Ancient Glass from Broborg, a Vitrified Swedish Hillfort
}

\author{
Bethany Matthews $^{1 *}$, Bruce Arey ${ }^{1}$, Carolyn Pearce $^{2}$, Albert Kruger $^{3}$ \\ 1. Nuclear Science Division, Pacific Northwest National Laboratory, Richland, WA, USA. \\ 2. Earth Systems Science Division, Pacific Northwest National Laboratory, Richland, WA, USA. \\ 3. United States Department of Energy, Office of River Protection, Richland, WA, USA. \\ *Corresponding author: bethany.matthews@pnnl.gov
}

Use of dual-beam focused ion beam scanning electron microscopes (FIB SEMs) has become standard of specimen preparation for scanning transmission electron microscopy (STEM) analysis as it allows siteselective sampling while viewing in the microscope. However, occasionally the area of interest lies below the exposed surface, or a depth profile is required from the surface down into the sample. Many conventional methods used to expose material may damage or change the material of interest or may be unfeasible. For instance, mechanical milling or polishing may cause mechanical stress, while methods such as etching can chemically alter the sample. Ion milling, such as by FIB, can be slow and can cause surface defects by ion implantation.

Pulsed laser ablation has an advantage over other techniques for removing materials, as it employs a highly focused laser which has a brief pulse duration to limit exposure damage on the sample. Brief pulses allow for an increase in ablation rate by increasing incident power on the sample with fewer damaging effects. It has been shown that light-matter interactions using an ultrafast pulse width do not significantly affect or damage the material left behind [1]. Here we explore the use of a femtosecond pulsed $1030 \mathrm{~nm}$ laser in conjunction with a plasma dual-beam fib to study the physical and chemical alteration features at and beneath the surface of ancient glass from Broborg, which is a hillfort in Sweden.

Broborg hillfort glass is considered as an analogue to study the long-term effects of aging on low activity waste glass, used to immobilize radioactive waste at the Hanford Nuclear Site, WA. The chemical compositions of the two are comparable, and both have been weathered in a near-surface environment similar to the proposed disposal facility [2]. A glassy sample, which had been in contact with soil, was excavated from Broborg and examined for alteration features using a sample preparation and handling method we described in [2]. This sample offered the potential to understand the effects of long-term weather processes and, with the ability to manipulate the sample in the SEM, we were able to identify a region of interest to explore these effects below the surface. With the laser, we sectioned incrementally by milling with the laser, polishing with the ion beam, and imaging with the electron beam, thereby creating a series of images to reconstruct the volume of material and to produce a depth profile.

The final face exposed by the laser was analyzed by energy dispersive x-ray spectroscopy (EDS) to identify material regions of interest. Cracks that were exposed by the laser showed interesting chemistry, so from those regions, cross-sectional STEM specimen were lifted in a dual beam FIB. The specimens were then studied in a FEI Titan for chemical differences and phase contrast. Within the cracks were found a variety of glass alteration phases, particularly along the edges of the crack, where the effects of weathering can be seen. 


\section{References:}

[1] J Herman et al., Applied Surface Science (2006), p. 4814.

[2] JL Weaver et al., International Journal of Applied Glass Science (2018), p. 1.

[3] We would like to thank Thermo Fisher for use of their laser/PFIB, Steven Randolph and Remco Geurts for their expertise on the laser/PFIB work, and the United States Department of Energy Office of River Protection for their support.
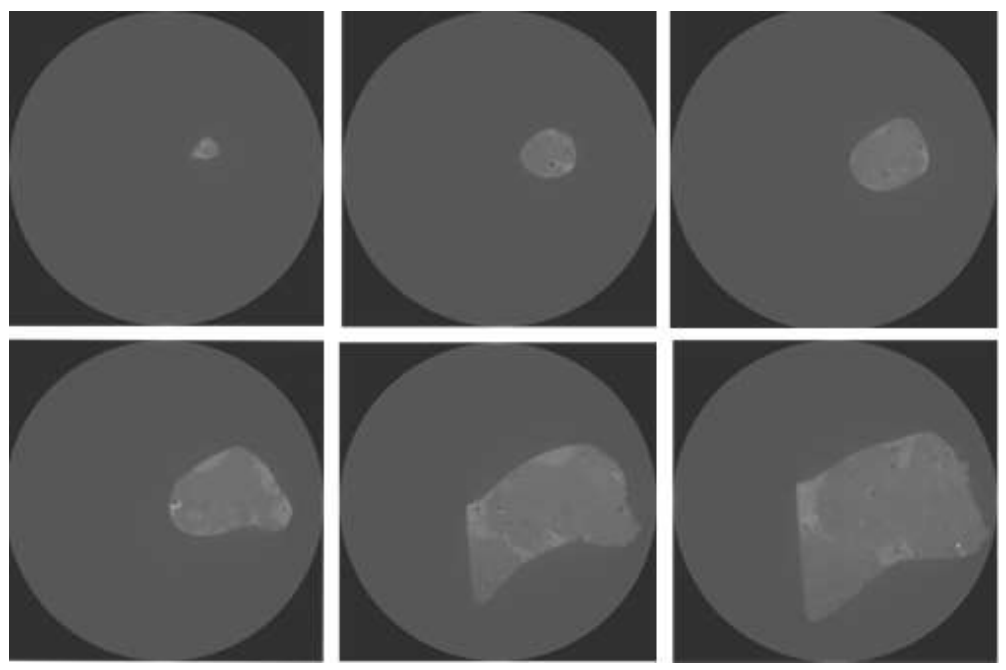

Figure 1. Images taken during serial sectioning of the sample were used to for a reconstruction of the sample.
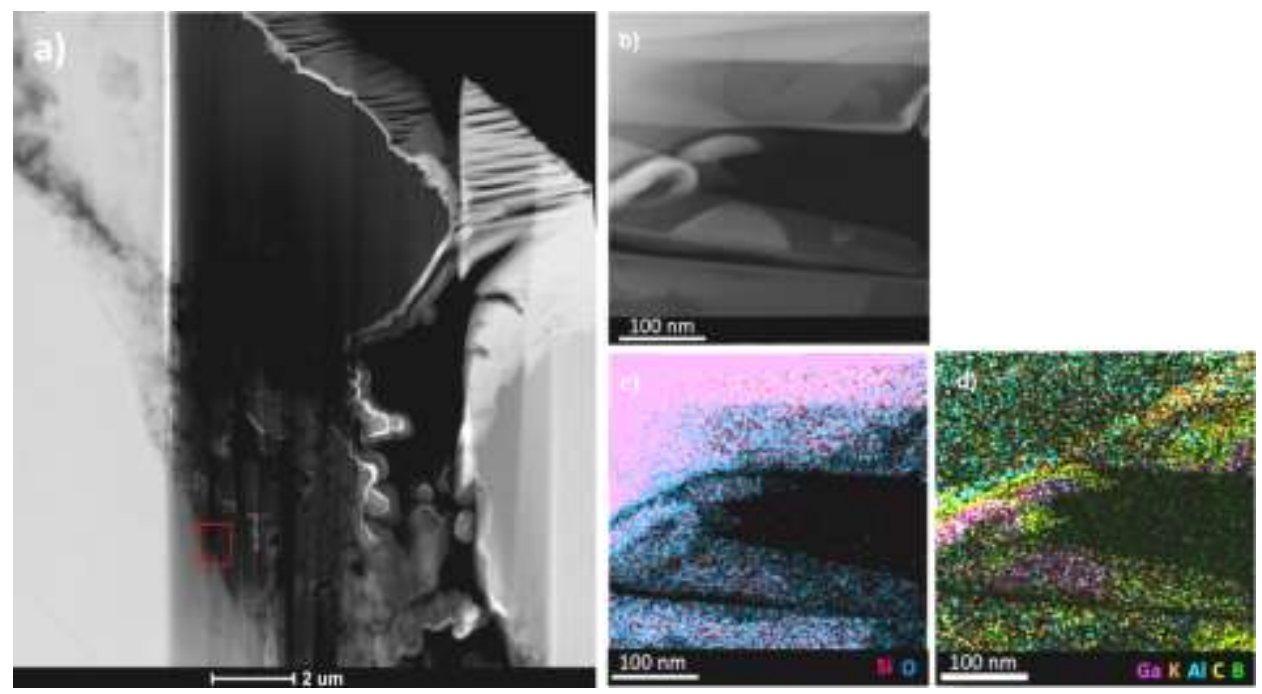

Figure 2. a) High angle annular dark field (HAADF) STEM image of the cross-sectional sample. The red box indicates the region where EDS maps were taken. HAADF image (b) of the indicated region near the crack edge. Overlaid EDS maps of Si and $\mathrm{O}(\mathrm{c})$ and of trace materials (d) for the region. 